chiều về sự cần thiết của việc sáp nhập TTKDYTQT vào $\mathrm{CDC}$ tỉnh/thành phố cho công tác Kiểm dịch y tế biên giới. Sau khi sáp nhập, cơ cấu tổ chức, chức năng nhiệm vụ, cơ sở vật chất, trang thiết bị, kế hoạch và quản lý chương trình ứng phó với dịch bệnh truyền nhiếm và các sự kiện y tế công cộng tại các Trung tâm không có sự thay đổi nhiêu. Việc sáp nhập cho thây đã giảm được số lượng cán bộ làm công tác quản trị, hành chính. Trong khi nguồn nhân lực tại các khoa phòng tăng, số lượng cán bộ làm công tác chuyên môn kiểm dịch y tế biên giới giảm. Năng lực xét nghiệm tại các trung tâm được cải thiện đáng kể do các $C D C$ đều có hệ thống phòng xét nghiệm đạt tiêu chuẩn. Năng lực tài chính bị phân hóa giữa các địa phương.

\section{TÀI LIẸU THAM KHẢO}

1. WHO. 2005. International Healtlh Regulations.
Đường dẫn: https://www.who.int/health-topics/ international-health-regulations \#tab $=\operatorname{tab} 1$

2. Nghị định của Thủ tướng Chính phủ số 248TTg, ngày 19 tháng 5 năm 1958 tổ chức việc kiểm dịch tại các hải cảng, sân bay, cửa khẩu quan trọng khác dọc theo biên giới nước Việt Nam Dân chủ Công hoà.

3. Ban Chấp Hành Trung Ương. 2017. Nghị Quyết $18-N Q / T W$. Mô̂t số vấn đề về tiếp tục đổi mới, sắp xếp tô chức bộ máy của hệ thống chính trị tinh gọn, hoạt động hiệu lực, hiệu quả.

4. Ban Chấp Hành Trung Ương. 2017. Nghi Quyết 19-NQ/TW. Về tiếp tục đổi mới hệ thống tổ chức và quản lý, nâng cao chất lượng và hiệu quả hoạt động của các đơn vị sự nghiệp công lập.

5. Ban Chấp Hành Trung Ương. 2017. Nghị quyết Hô̂i nghi Trung ương 6 (khóa XII) về đổi mới, sắp xểp tổ chức bộ máy của hệ thống chính trị.

6. Bô̂ Y tế. 2017. Thông tư 26/2017/TT-BYYT Hướng dẫn chức năng, nhiệm vụ, quyền hạn và cơ cấu tổ chức của Trung tâm kiểm soát bệnh tật tỉnh, thành phố trực thuộc trung ương.

\title{
MộT Số YẾU TỐ ẢNH HƯỞNG ĐẾN KẾT QUẢ TẠO HÌNH KHUYẾT HỔNG PHẦN MỀM NGÓN TAY BẰNG VAT CUỐNG LIỀN TẠI CHỖ
}

\section{TÓM TẮT}

Đă̆t vấn đề: Việc xác định các yếu tố ảnh hưởng đến kết quả phẫu thuật sẽ góp phân đánh giá được ưu và nhược điểm của tứng loại và đó chính là cơ sở thực tiễn để lựa chọn vạt. Phương pháp nghiên cứu: Nghiên cứu can thiệp lâm sàng không đối chứng được tiến hành trên 115 bệnh nhân với 130 khuyết hổng phần mềm ngón tay được tạo hình bằng vat cuống liền tại chỗ tại khoa phấu thuật tạo hình bệnh viện đa khoa Xanh Pôn và bệnh viện hữ nghị Việt Tiệp Hải Phòng. Kết quả: Trong tổng số 130 vạt cống liển tai chố có 95 vat sử dung dang ngẫu nhiên, 35 vat được sử dụng dạng trục mạch. Tỷ lệ sông hoàn toàn của vạt dạng ngẫu nhiên là 94/95, của vạt dạng truc mạch là 26/35. Theo dõi khả năng phục hồi cảm giác sau mổ 3-6 tháng được 110/130 ngón tay ttrong đó có $30 / 76$ vạt ngẫu nhiên và $2 / 34$ vạt dạng trục mạch phục hồi cảm giác ở mức độ đây đủ là S4. Kểt luẩn: Các yếu tố nguồn cấp máu tại vạt dạng ngấu nhiên hay trục mạch và cách thức di chuyến của vat dạng xuôi dòng hay ngược dòng có mối liên quan chặt chẽ đến mức độ sống và khả năng phục hồi cảm giác tại vạt.

Tư khóa: Khuyết phần mềm ngón tay, vạt tại chố, vạt ngẫu nhiên, vạt trục mạch.

\footnotetext{
${ }^{1}$ Trường Đại học Y Dược Hải Phòng

${ }^{2}$ Bênh viên Trung ương Quân đồi 108

Chịu trách nhiệm chính: Nguyễn Đức Tiến

Email: ndtien@hpmu.edu.vn

Ngày nhận bài: 10.5.2021

Ngày phản biên khoa học: 28.6.2021

Ngày duyệt bài: 9.7.2021
}

\section{SUMMARY \\ VARIOUS FACTORS AFFECTING THE SOFT TISSUE RECONSTRUCTION OF FINGERS \\ RESULTS USING LOCAL PEDICLE FLAP}

Background: Pedicled perforator flap in hand is variety and flexible motion. Purpose: Describing characteristics of soft tissue defects and evaluating results of reconstructing this injuries by local pedicled perforator flaps at Viet Tiep Hospital from 1/2018 to 9/2018. Method: Uncontrolled clinical interventional study. Results: 11 patients with 13 soft tissue defects were treated by 15 local pedicled perforator flaps. The minimum size of flap was $1,5 \times 2 \mathrm{~cm}$ and the maximum one was $3 \times 9 \mathrm{~cm}$. There were 14 flaps which were survived and one flap was necrosis at the one third lower area of flap. 14/15 donor sites were performed thickness skin grafts and they were survived. 1/15 flap was sutured directly to heal by primary intention. Conclusion: Local pedicled perforator flaps are trustful material to reconstruct soft tissue defects of fingers.

Keywords: Finger soft tissue defect, perforator flap, local flap.

\section{I. ĐĂT VẤN ĐỀ}

Theo Robert W. Beasley [1]: Có 3 yếu tố quan trong khi lựa chọn vạt tổ chức để tạo hình khuyết hống phần mềm ngón tay đó là: Bảo tồn được chức năng xúc giác tinh tế của ngón tay, ít làm tổn hại nơi cho vạt và vạt áp dụng có tính khả thi và tin cậy có thể dự đoán được kết quả phẫu thuật. 
Vạt tại chỗ là một trong những kỹ thuật được lựa chọn đầu tiên để che phủ các khuyết phần mềm búp ngón tay do có các ưu điểm: Không làm tổn thương thêm các ngón lành, kỹ thuật tương đối đơn giản thời gian phẫu thuật nhanh, màu sắc cấu trúc vạt tương đồng với xung quanh, bảo tồn được mạch máu có thể bảo tồn cả thần kinh đi kèm. Bệnh nhân phục hồi nhanh cả về chức năng và hình thái của bàn ngón tay [2]. Tranquilli-Leali là người đầu tiên sử dụng vạt tại chỗ để bảo tồn khuyết phần mềm búp ngón tay năm 1935 [3]. Từ đó đến nay đã có rất nhiều loai vạt được áp dụng để tạo hình các khuyết hổng phần mềm ngón tay. Việc xác định các yếu tố ảnh hưởng đến kết quả phẫu thuật sẽ góp phần đánh giá được ưu và nhược điểm của tứng loại và đó chính là cơ sở thực tiễn để lựa chọn vạt. Vì vậy chúng tôi tiến hành nghiên cứu đề tài này nhằm hai mục tiêu: "Xác định một số yếu tố ảnh hưởng đến kêt quả tạo hình khuyêt hỏng phần mềm ngón tay băng vạt tại chỗ"

\section{II. ĐỐI TƯỢNG VÀ PHƯƠNG PHÁP NGHIÊN CỨU}

1. Đối tượng nghiên cứu. Nghiên cứu can thiệp tiến cứu không đối chứng được tiến hành trên 115 BN với 130 vết thương KPHM NT có chỉ định phẫu thuật che phủ KHPM bằng vạt cuống liền tại chố tại khoa phẫu thuật Tạo Hình bệnh viện đa khoa Xanh - Pôn và bệnh viện Hữu Nghị Việt Tiệp Hải Phòng từ 10/2016 đến 12/2019

\subsection{Tiêu chuân lứa chọn.}

- Bao gồm tất cả các bệnh nhân có tổn thương KHPM NT do các nguyên nhân khác nhau được tạo hình che phủ bằng vạt cuống liền tại chỗ.

- Các BN có KHPM NT sau khi điều trị nhễm trùng đã ổn định.

- Các BN có KHPM NT sau phẫu thuật cắt sẹo giải phóng co kéo do di chứng bỏng, di chứng chấn thương...

\subsection{Tiêu chuẩn loại trừ.}

- Bệnh nhân có các tổn thương khác kết hợp tại ngón tay bị khuyết hổng phần mềm: Gãy xương hở, trật khớp, đứt gân.

- Bệnh nhân có khuyết hổng phần mềm ngón tay khổng được tạo hình che phủ bằng vạt mạch xuyên cuống liền tại chỗ.

- Bệnh nhân không đồng ý tham gia nghiên cứu.

\section{Phương pháp nghiên cứu.}

2.1 Địa điểm và thời gian nghiên cứu.

Địa điểm nghiên cứu: Khoa phẫu thuật tạo hình thẩm mỹ bệnh viện đa khoa Xanh Pôn và khoa phẫu thuật tạo hình thẩm mỹ bệnh viện hữu nghị Việt Tiệp Hải Phòng.

Thời gian nghiên cứu: Từ tháng 10/2016 đến tháng 12/2020.

2.2 Thiết kế nghiên cứu: Nghiên cứu can thiệp không đối chứng.

2.3 Cách chọn mẫu. Chọn mẫu thuật tiên: Lựa chọn tất cả các bệnh nhân đủ tiêu chuẩn lựa chọn trong thời gian nghiên cứu.

\section{4 Đạo đức trong nghiên cứu.}

- Phẫu thuật che phủ khuyết hổng phần mềm ngón tay bằng các vạt tại chỗ được thực hiện theo đúng quy trình kỹ thuật Bộ Y tế.

- Tất cả các bệnh nhân được giải thích trước khi tham gia vào nghiên cứu, bệnh nhân có quyền từ chối tham gia vào bất kỳ giai đoạn nào của quá trình nghiên cứu, các bênh nhân đồng ý và không đồng ý tham gia vào nghiên cứu được điều trị theo quy trình của Bộ Y Tế.

- Nghiên cứu được tiến hành theo đúng đề cương nghiên cứu đã được hội đồng đạo đức nghiên cứu $Y$ sinh học trường đại học $Y$ Hà Nội thông qua.

\section{KẾT QUẢ NGHIÊN CỨU}

Qua nghiên cứu trên 115 bệnh nhân với 130 khuyết hổng phần mềm ngón tay được tạo hình bằng vạt cuống liền tại chỗ chúng tôi nhận thấy:

Bảng 3.1: Môi liên quan giữa nguồn nuôi vạt với mức độ sống của vạt

\begin{tabular}{|c|c|c|c|c|c|c|c|}
\hline \multirow{2}{*}{ Mức độ sống vạt } & \multicolumn{2}{|c|}{ Ngẫu nhiên } & \multicolumn{2}{|c|}{$\begin{array}{l}\text { Vạt trục } \\
\text { mạch }\end{array}$} & \multirow{2}{*}{ Tổng } & \multirow{2}{*}{$\begin{array}{c}\text { OR } \\
(95 \% \mathrm{CI})\end{array}$} & \multirow{2}{*}{ p } \\
\hline & $\mathbf{S L}$ & $\%$ & SL & $\%$ & & & \\
\hline Sống hoàn toàn & 94 & 78,3 & 26 & 21,7 & 120 & \multirow{3}{*}{$\begin{array}{c}32,5 \\
(3,9-268,7)\end{array}$} & \multirow{3}{*}{$<0,001$} \\
\hline Hoại tử một phần & 1 & 10,0 & 9 & 90,0 & 10 & & \\
\hline Tống & 95 & 73,1 & 35 & 26,9 & 130 & & \\
\hline
\end{tabular}

Nhận xét: Kết quả cho thấy vạt ngấu nhiên sau mố sống hoàn toàn cao hơn nhóm hoại tử một phần. Sự khác biệt có ý nghĩa thống kê với $p<0,001$.

Sau mổ trong vòng 3-6 tháng chúng tôi theo dõi được 110 bệnh nhân chúng tôi nhận thấy: Sau mổ tất cả các vạt đều có cảm giác, sự phục hồi cảm giác nơi cho và nơi nhận vạ chịu ảnh hưởng của nhiêu yếu tố khác nhau trong đó có cách di chuyển của vạt.

Bảng 3.2: Môi liên quan giữa nguồn nuôi vạt với khả năng phục hồi cảm giác sau mổ 36 tháng 


\begin{tabular}{|c|c|c|c|c|c|c|c|c|}
\hline \multirow{2}{*}{\multicolumn{2}{|c|}{$\begin{array}{l}\text { Nguî̀n nuôi vạt } \\
\text { Mức độ phụ̂c hồi cảm } \\
\text { giác sau mổ 3-6 tháng }\end{array}$}} & \multicolumn{2}{|c|}{ Ngấu nhiên } & \multicolumn{2}{|c|}{ Vạt trục mạch } & \multirow[b]{2}{*}{ Tổng } & \multirow{2}{*}{$\begin{array}{c}\text { OR } \\
(95 \% \mathrm{CI})\end{array}$} & \multirow[b]{2}{*}{$\mathbf{p}$} \\
\hline & & SL & $\%$ & SL & $\%$ & & & \\
\hline \multirow{2}{*}{ Nơi cho vạt } & S4 & 61 & 81,3 & 14 & 18,7 & 75 & \multirow{2}{*}{$\begin{array}{c}5,8 \\
(2,4-14,1)\end{array}$} & \multirow{2}{*}{$<0,001$} \\
\hline & $\leq \mathrm{S} 3+$ & 15 & 42,9 & 20 & 57,1 & 35 & & \\
\hline \multirow{2}{*}{ Nơi nhận vạt } & S4 & 30 & 93,8 & 2 & 6,3 & 32 & \multirow{2}{*}{$\begin{array}{c}10,4 \\
(2,3-46,8)\end{array}$} & \multirow[b]{2}{*}{$<0,001$} \\
\hline & $\leq \mathrm{S} 3+$ & 46 & 59,0 & 32 & 41,0 & 78 & & \\
\hline
\end{tabular}

Nhận xét: Kết quả bảng 3.2 cho thấy nguồn nuôi ngẫu nhiên có tỷ lệ phục hồi cảm giác sau mố 3-6 tháng ở mức $S 4$ cả 2 nơi cho và nhận vạt $(81,3 \%$ và $93,8 \%)$ cao hơn nhóm $\leq \mathrm{S} 3+(42,9 \%$ và $59,0 \%)$. Sự khác biệt có ý nghĩa thống kề với $p<0,001$.

\section{BÀN LUÂ̂N}

1. Các yếu tố ảnh hưởng đến mức độ sống của vạt. Kết quả bảng 3.1 cho thấy vạt ngẫu nhiên có sức sống cao hơn so với vạt dạng trục mạch 78,3\% nguồn nuôi vạt theo phương pháp ngẫu nhiên có vạt sống hoàn toàn, tỷ lệ này là $10,0 \%$ ở nhóm hoại tử. Sự khác biệt có ý nghĩa thống kê với $p<0,001$. Theo kết quả của nhiều tác giả nghiên cứu về vạt ngẫu nhiên đều nhận thấy sức sông của vạt dạng này rất cao, khổng bao giờ có hiện tượng hoại tử hoàn toàn vạt, tỷ lệ vạt hoại tử dưới $1 / 3$ diện tích rất thấp và các tác giả thường để liền thương tự nhiên mà không cần can thiệp gì thêm. Theo Atasoy và cs (1970) [4] nghiên cứu trên 62 vạt có 2 vạt bị họi tử một phân. Theo nghiên cứu của Aboulwafa Ahmed and Emara Sherif (2013)[5]: trong 170 vạt da được phẫu tích có 166 vạt da sống hoàn toàn, chỉ có 4 vạt da bị hoại tử một phần: điều này chứng tỏ sức sống của vạt tại chổ vùng búp ngón tay là rất cao, và vat tại chỗ là một lựa chọn an toàn cho hình thái tổn thương búp ngón.

Mức độ sống của vạt trục mạch phụ thục vào rất nhiêu yếu tố trong đó có yếu tố trong đó cách di chuyển của vạt vạt là một trong những yếu tố rất quan trong. Khi di chuyển xuôi dòng vạt có khả năng sống tốt hơn vạt khi di chuyển dạng ngược dòng. Theo kết quả nghiên cứu của Chao Chen và cs (2014) [6]: trong số 24 vạt có $11 \%$ vạt bị hoại tử một phânn, trong đó vạt cuống nuôi ngược dòng có tỷ lệ hoại tử một phần cao hơn chiếm $27 \%$, tất cả các trường hợp này đều chăm sóc và lành thương tự nhiên không cần can thiệp thì hai.

Rõ ràng khả năng sống của các vat cuống liền tại chỗ vùng bàn tay có những điểm khác biệt với các vùng khác: Các nghiên cứu đều nhận thây khả năng sống của vạt ngẫu nhiên cao hởn vạt dạng trục mạch, vạt di chuyển dạng ngược dòng có mức độ sống thấp hơn vạt di chuyển ngược dòng. Trong quá trình nghiên cứu chúng tôi nhận thấy có hai lý do chính dẫn đến vấn đề này. Thứ nhất các mach vùng ngón tay có kích thước rất nhỏ đó rất dễ bi tổn thương trong quá trình bóc tách, khi di chuyển theo kiểu ngược dòng rất dễ bị xoắn gây nghẹt cuống vạt. Thứ hai ở ngón tay do đặc điểm giải phẫu động mạch cấp máu nằm phía gan tay, tĩnh mậ về chủ yếu phần mu tay, tĩnh mạch tùy hành động mạch kích thước nhỏ nên khi di chuyển ngược dòng rất dễ dẫn đến tình trạng phù nề ứ máu tại vạt.

2. Các yếu tố ảnh hưởng đến khả năng phục hòi cảm giác của vạt. Kết quả nghiên cứu cho thấy các vạt di chuyển kiểu ngẫu nhiên có kahr năng phục hòi cảm giác sau mổ gai đoạn 3-6 tháng tốt hớn vạt dạng trục mach. So sánh với kết quả nghiên cứu về khả năng phục hồi cảm giác giữa hai loại vạt ngấu nhiên và vạt trục mạch của các tác giả khác chúng tôi nhận thây:

Vạt ngẫu nhiên: Sungur Nezih và CS (2012): [7] tất cả các vạt sau mổ đều có khả năng nhận biết đước 2 điểm phân biệt ở khoảng cách dưới $6 \mathrm{~mm}$. Theo nghiên cứu của [5] Aboulwafa Ahmed and Emara Sherif (2013): nghiên cứu trên 170 búp ngón tay được phẫu thuật tạo hình bằng vạt tại chỗ được đánh giá sự phục hồi cảm giác sau mổ > 3 tháng: (từ 3-22 tháng trung bình là 9 tháng) cho thây khả năng nhận biết 2 điểm phân biệt của búp ngón tay sau mổ là từ $4-5 \mathrm{~mm}$, trung bình là $4,5 \mathrm{~mm}$. Điều này càng chứng tỏ được ưu điểm vượt trội của vạt tại chỗ so với các vạt khác vì đây là vạt da có khả năng phục hồi cảm giác rất tốt.

Vat truc: Theo Hastings H (1987) [8]: Khi đánh giá khả năng nhận biết hai điểm phân biệt của vat diều bay xuôi dòng có bảo tồn cả mạch và thần kinh của nhánh mu đốt bàn 2 nơi cho vạt được ghép da dây kết quả sau mổ tác giả nhận thây: Sau 10 tuần BN mới có cảm giác tại vạt, sau 10 tuần khoảng cách nhận biết 2 điểm phân biệt là $12 \mathrm{~mm}$. Sau 12 tuần khoảng cách nhận biết 2 điểm phân biệt tại vạt là $5 \mathrm{~mm}$, khả năng nhận biết hai điểm phân biệt tại bờ quay ngón trỏ là $10 \mathrm{~mm}$. Theo kết quả nghiển cứu của Chao Chen và cs (2014) [6] nghiên cứu trên 24 
trường hợp sử dụng vạt nhánh xuyên động mạch mu đốt bàn xuôi dòng và ngược dòng che phủ KHPM ngón tay khoảng cách nhận biết hai điểm phân biệt ở trạng thái tĩnh của vạt xuôi dòng là $8,3 \mathrm{~mm}$ vạt ngược dòng trung bình là $10,4 \mathrm{~mm}$.

Kết quả nghiên cứu của chúng tôi có sự tương đồng với kết quả nghiên cứu của các tác giả khác. Tất cả đều nhận thấy sự khác biệt về khả năng phục hồi cảm giác của các vạt dạng ngẫu nhiên sớm hơn và tốt hơn các vạt dạng trục mạch. Các vạt di chuyển xuôi dòng phục hồi cảm giác tốt hơn các vạt di chuyển ngược dòng.

\section{KẾT LUẬN}

Có nhiều yếu tố khác nhau ảnh hưởng đến kết quả tạo hình khuyết hổng phần mềm ngón tay bằng vạt cuống liền tại chỗ. Trong đó yếu tố nguồn cấp máu tại vạt và cách thức di chuyển của vạt dạng xuôi dòng hay ngược dòng có mối liên quan chặt chẽ đến mức độ sống và khả năng phục hồi cảm giác tại vạt. Vạt ngẫu nhiên di chuyển xuôi dòng có mức độ sống cao nhất và có khả năng phục hồi cảm giác sớm nhất và tốt nhất.

\section{TÀI LIÊU THAM KHẢO}

1. Beasley, R.W. (1983). Principles of soft tissue replacement for the hand. The Journal of Hand Surgery 8(5):781-784.

2. De, S.D. and M. Sandeep J. Sebastin (2020). Soft tissue coverage of the digits and hand. Hand Clin, 36(1):97-105.

3. Rehim, S.A. and K.C. Chung (2015). Local Flaps of The Hand. Hand Clin, 2014 May ; 30(2) 137-151.

4. Atasoy, E., et al. (1970). Reconstruction of the Amputated Finger Tip with a Triangular Volar Flap J Bone Joint Surg Am, 52(5), pp 921-926.

5. Aboulwafa, A. and S. Emara (2013). Versatility of Homodigital Islandized Lateral V-Y Flap for Reconstruction of Fingertips and Amputation Stumps. Egypt, J. Plast. Reconstr. Surg., Vol. 37, No. 1, January: 89-96, 2013.

6. Chen, $C_{\text {., }} \mathbf{W}$. Zhang, and P. Tang (2014). Direct and reversed dorsal digito-metacarpal flaps: A review of 24 cases. Care Injured, 45:805-812.

7. Sungur, N., et al. (2012). Bilateral V-Y rotation advancement flap for fingertip amputations. American Association for Hand Surgery 2012, 7:79-85.

8. Hastings, H. (1987). Dual innervated index to thumb cross finger or island flap reconstruction. Microsurgery, 8(3):168-172.

\section{NGHIÊN CỨU CÁC YẾU TỐ NGUY CƠ LÀM TĂNG TỶ LÊ MẮC HUYẾT KHỐI TĨNH MẠCH SAU PHẪU THUẬT TIM NGỰC}

\section{TÓM TẮT}

Nghiên cứu được thực hiện nhằm xác định tỷ lệ và các yếu tố nguy cớ huyểt khối tĩnh mạch ở người bệnh phẫu thuật tim ngực bằng việc áp dụng mô hình thang điểm nguy cơ Caprini hiệu chỉnh. Nghiên cứu sử dụng thiết kể mô tả cẵt ngang được tiến hành trên 35612 người bệnh phẫu thuật tim ngực từ $1 / 2017$ đến 12/2018. Tất cả người bệnh được đánh giá điểm nguy cơ trước phẫu thuât và được theo dõi trong vòng 30 ngà̃y sau phẫu thuật. Kết quả cho thấy tỷ lệ HKTM sau phẫu thuất tim ngức 30 ngày là $0,22 \%$ (78/35612). Nguy cơ mắc HKTM ở người có tổng điểm caprini 7-8 điểm cao gấp 7,13 lần so với người bệnh ở nhóm điểm Caprini 0-2. Các yễú tố nguy cơ làm tăng khả năng mắc HKTM sau phẫu thuật bao gồm: Tuổi, giới tính, suy tĩnh mạch ngoại vi ${ }_{L}$ tiểu đường và đặc biệt là tiên sử huyết khối trước phầu thuật.

Tư khóa: Huyết khối tĩnh mạch, phẫu thuật tim ngực, yếu tố nguy cơ, điểm Caprini

\footnotetext{
${ }^{1}$ Trường Đại học Y Hà Nội

²Bệnh viện Bạch Mai

Chịu trách nhiệm chính: Bùi Mỹ Hạnh

Email: buimyhanh@hmu.edu.vn

Ngày nhận bài: 10.5.2021

Ngày phản biện khoa học: 28.6.2021

Ngày duyệt bài: 9.7.2021
}

\section{Bùi Mỹ Hạnh ${ }^{1}$, Dương Đức Hùng ${ }^{2}$, Đoàn Quốc Hưng ${ }^{1}$}

\section{SUMMARY}

\section{RISK FACTORS OF VENOUS THROMBOEMBOLISM AFTER THORACIC SURGERY: A CASE-CONTROL STUDY FROM NATIONAL INSURANCE DATA}

Venous thromboembolism is an uncommon complication after thoracic surgery. However, it is a dangerous complication because it is often overlooked due to its infrequent and silent symptoms. The study is carried out to determine the rate and risk factors of venous thrombosis in patients who experienced thoracic surgery by applying adjusted Caprini risk assessement model. This study using descriptive cross section design was conducted on 35,612 patients undergoing thoracic surgery from $1 / 2017$ to $12 / 2018$. All patients were assessed for risk prior to surgery and supervised for 30 days postoperatively. The results showed that the rate of venous thromboembolism after 30-day thoracic surgery was calculated as $0.22 \%$ (78/35612). The risk of developing postoperative venous thromembolism in patients with a total caprini score of 7-8 points was estimated as 7.13 times which is higher than that of patients in the group with Caprini score 0-2. The risk factors increasing the likelihood of postoperative venous thromboembolism include: Age, sex, peripheral vascular disease, varicose cein, diabetes and especially history of thrombosis. 